\title{
EFFECT OF GLASS COVER ANGLES ON THE PERFORMANCE OF DOUBLE SLOPE SOLAR STILL: A CFD SIMULATION ANALYSIS
}

\author{
AKKALA SIVA RAM ${ }^{1}$ \& AJAY KUMAR KAVITI ${ }^{2}$ \\ ${ }^{\text {I}}$ P.G scholar, Department of Mechanical Engineering, VNR Vignana Jyothi Institute of Engineering and Technology, \\ Hyderabad, India
}

${ }^{2}$ Associate Professor, Department of Mechanical Engineering, VNR Vignana Jyothi Institute of Engineering and Technology, Hyderabad, India

\begin{abstract}
The main aim of this paper is to conduct a numerical simulation study using the CFD on the performance of double slope solar still for the various glass cover inclination angles such as $25^{\circ}, 35^{\circ}$, and $45^{\circ}$. Nowadays, the CFD simulation study helps the engineers to prove the experimental work theoretically thereby diminishes the time and cost and provide reliable results. In this work, a 2-D CFD simulation study is carried out to investigate the heat and mass transfer in the solar still. The water flow in the solar still is assumed as an incompressible ideal gas, steady, laminar, and 2-D. The COUPLED algorithm is employed to solve the energy, momentum, and continuity equations for this numerical simulation study. The CFD simulation results provide a good acceptable agreement when compared to the published experimental data in the literature. From the CFD simulation results, it concluded that $35^{\circ}$ glass cover angle exhibit optimum and accurate results in contrast to the other glass cover angles such as $25^{\circ}$ and $45^{\circ}$ by evaluating the contours of velocity, temperature, streamline functions, and vapor mass fraction of water.

KEYWORDS: Double Slope Solar Still, CFD Simulation, Heat and Mass Transfer, Solar Desalination
\end{abstract}

Received: Jun 08, 2020; Accepted: Jun 28, 2020; Published: Sep 19, 2020; Paper Id.: IJMPERDJUN20201338

\section{INTRODUCTION}

Water is the primary source of life for humanity. All over the world, $97 \%$ of water is in the oceans, $2 \%$ of water is in the icebergs and lakes, rivers, etc. Only $1 \%$ of water is there for the fundamental needs of human beings[1]. The natural resources of the earth decrease day by day due to global warming, the increased population of the world, and the rapid development of industrial sewages, etc. Because of these reasons, the quality of drinking water is diminishing and diseases such as cholera, hepatitis, and diarrhea, etc can be easily transmitted to human beings[2].

So, an alternate solution is required for enhancing the quality of pure water and various techniques are available for getting the potable water which is thermal, membrane, and renewable energy methods. Out of these methods, renewable energy solar desalination is the most economical[3]. The device which converts saline or brackish water into pure or potable water is known as a solar still and there are several designs and modifications of solar stills are available which are single slope solar still, double slope solar still, pyramid type solar still, triangular solar still, spherical and hemispherical solar stills, tubular solar stills, active and passive type solar stills, etc[4]. In passive type solar stills, internal modifications such as stones, jute cloths, sensible energy storage materials, sponges, dung cakes, etc can be used for enhancing the performance of the still. In active type solar stills, the 
devices such as the condenser, blower, fan, cooling covers, Fresnel lens, flat plate solar collectors, solar concentrators, etc can be employed for getting more output from the solar stills [5].After that researchers worked the parameters affecting the performance of the SS which are controllable and non-controllable. The controllable parameters are depth of water, size, and shape of the SS, etc and non-controllable parameters are wind velocity, solar intensity, and climatic conditions. The manufacturing cost of the solar stills is cheap because these devices are produced with the locally available materials[6].

Nader et al. [7] estimated the water productivity and convection heat transfer coefficients in tubular solar still by utilizing the theoretical and CFD simulation analysis. The author concluded from CFD results that the condensation rate is more at the glass cover and one recirculating zone is there, it rotates in the clockwise direction in the inside of the tubular solar still. Rashidi et al.[8] Investigated the performance of single slope solar still by providing an optimized partitioning inside of the solar still with the help of using the CFD simulation and RSM (Response surface methodology) techniques. The results indicated that providing partition inside the solar still improves the vortices in smaller sizes which enhances still efficiency and dispense the adequate time for energy transfer between the water and glass surface.

Javad and Rahbar [9] performed a numerical study by using the CFD simulation for estimating the convective heat transfer coefficients in single slope solar still. The author used the theoretical based SIMPLE algorithm for solving numerical equations and studied the effect of aspect ratio and Rayleigh number on the convective heat transfer coefficients. The results showed that the heat transfer coefficient is directly proportional to the Rayleigh number for a given aspect ratio. Similarly, for a given Rayleigh number, the heat transfer coefficient has an inverse effect on the aspect ratio. Esfahani and Rahbar [10] estimated the productivity of the single-slope solar still with the help of using the numerical and theoretical analysis and concluded that good acceptable agreement occurred between the CFD results and experimental data published in the literature. Jafarpur et al.[11] used the CFD transient modeling and compared the simulation of single slope solar still with the simulation multi-effect solar still and studied the contours of temperature, velocity, and vapor mass fraction of water.

In this present simulation study, a 2-D model of double slope solar still is simulated by using the CFD Ansys Fluent for evaluating the Bilal et al.[12] experimental work by considering the different cover angles such as $25^{\circ}, 35^{\circ}$, and $45^{\circ}$. The evaluation is done by analyzing the contours of velocity, temperature, stream functions, and vapor mass fraction values of water vapor. The anticipated result is that $35^{\circ}$ glass cover angle is an optimum inclination for the solar still under Jordan climatic conditions, it is numerically investigated.

\section{PROBLEM STATEMENT AND PHYSICAL DESCRIPTION}

In this present study, an experimental work of Bilal and co-authors [12] has been simulated with the aid of CFD Ansys Fluent for evaluating. The author worked on the double slope solar still by varying the glass cover inclination angles such as $15^{\circ}, 25^{\circ}, 35^{\circ}, 45^{\circ}$, and $55^{\circ}$. Here in this study, glass cover tilt angles of $25^{\circ}, 35^{\circ}$, and $45^{\circ}$ are considered for evaluating the simulations results with the experimental data. The schematic representation of the double slope solar still is depicted in Fig. 1 with the dimensions of length $0.5 \mathrm{~m}$, height $0.3 \mathrm{~m}$, and glass cover inclination of $35^{\circ}$. The water and glass cover surface temperatures are kept constant which are $65^{\circ} \mathrm{C}$ and $48^{\circ} \mathrm{C}$ taken from the literature. The sidewalls of the stills are assumed to be insulated and the assumption of water and air-water vapor mixture present in the solar stills is described in a schematic representation. Besides some more assumptions are considered based on the theoretical study for simulating the double slope solar still in the CFD which are 
- The water flow is laminar, steady, and 2-D.

- The air-water vapor mixture is assumed as an incompressible ideal gas with constant physical properties.

- The dissipation of viscous is negligible.

- The still is free of cavity dimensions.

- The temperature variation between the water and glass is assumed as $11^{0} \mathrm{C}$ taken from the literature.

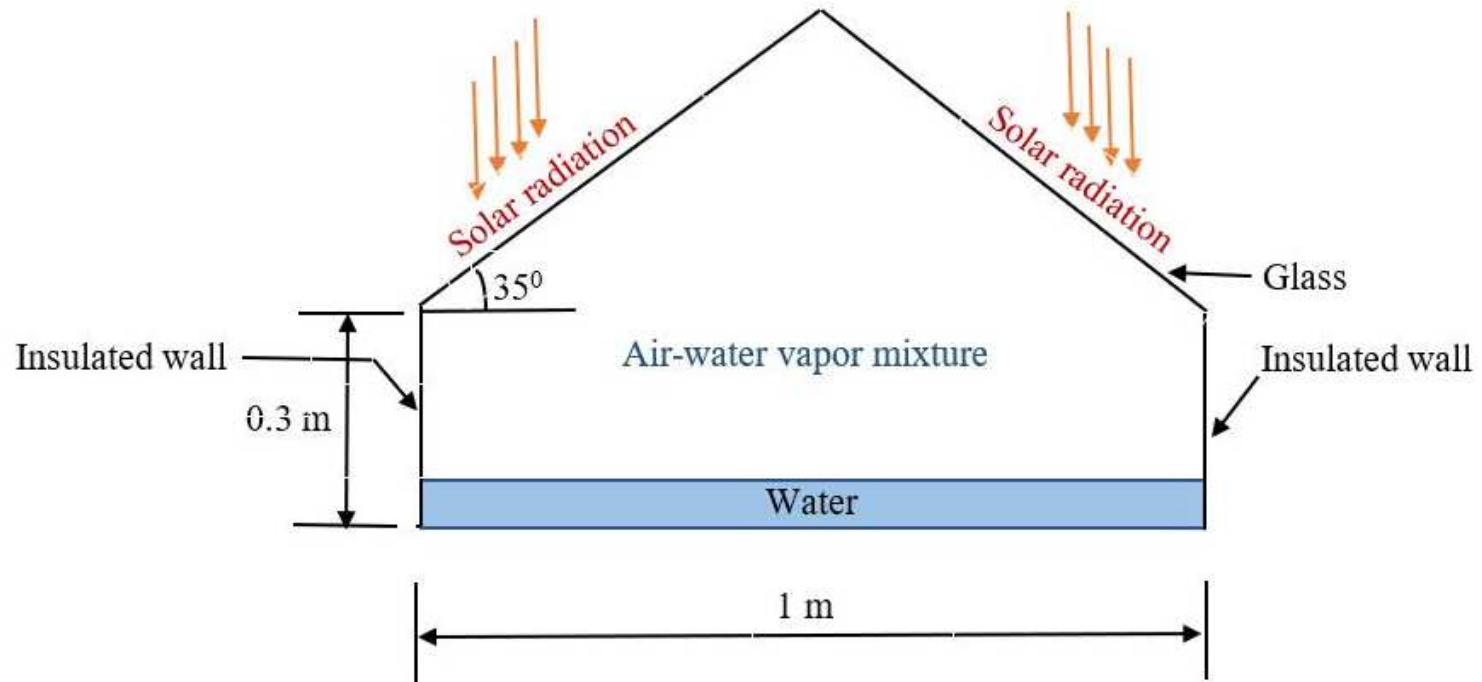

Figure 1: Schematic Representation of Double Slope Solar Still.

The 2-D mesh schematic representation of the simulation setup is described in Fig. 2 and the boundaries of the mesh are more refined where the variation of temperature and velocity gradients are varying rapidly. The number of elements developed for the mesh is 10098 and 1000 iterations are performed for getting the accurate results based on the system restrictions. The coupled algorithm method is opted for solving the numerical equations discussed in the mathematical modeling session and the iterations are solved with the help of the Thomas algorithm which is a line by line method. The contours of temperature, velocity, vapor mass of water, and stream functions were explained in the results and discussions session.

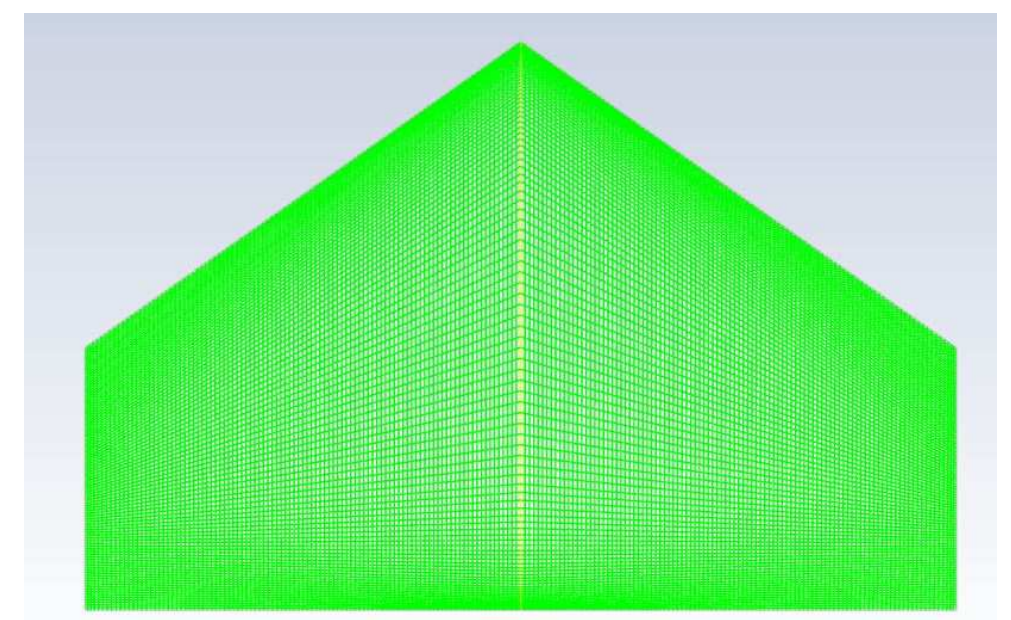

Figure 2: Schematic Representation of Generated Mesh in Double Slope Solar Still. 


\section{MATHEMATICAL MODELLING}

The governing equations of simulation such as continuity, momentum, energy, and boundary conditions given by Eslami et. al[11] and Jafarpur et al.[13] and are going to be discussed below.

The continuity equation is

$\frac{m}{d x}+\nabla(p v)=0$

Where $\rho=$ density.

and $v=$ time-averaged velocity vector.

The momentum equations for the water and air-water vapor mixture are as follows

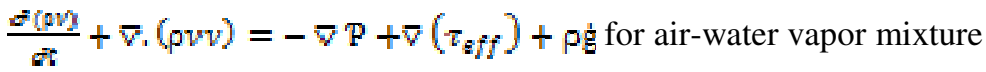

$$
\begin{aligned}
& \frac{e(p v)}{\theta t}+\nabla_{1}(\rho v v)=-\nabla \mathrm{P}+\bar{\nabla}(\mathrm{\sigma})+\rho \mathrm{g} \rho\left(T-T_{0}\right) \text { for water }
\end{aligned}
$$

Where $\beta=$ thermal expansion coefficient of water.

The energy equation can be obtained by solving the temperature distribution of the energy conservation equation in its various components such as glass, water, and air-water vapor mixture.

$$
\begin{aligned}
& \frac{\theta(p E)}{\Delta t}+\bar{V} \cdot(v(\rho E+P))=\bar{\nabla}\left(\lambda_{e f f} \nabla \mathrm{T}-\bar{\Xi}_{j} h_{E} \bar{l}\right)+S_{h}+S_{L} \text { for air-water vapor mixture }
\end{aligned}
$$

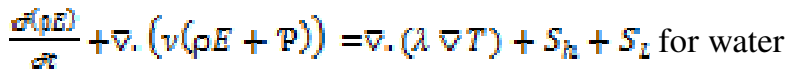

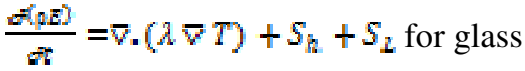

Where $\lambda_{e f f}=$ effective thermal conductivity.

$\mathbf{h}_{\boldsymbol{E}}$ and $\hat{j}_{j}=$ sensible enthalpy and diffusive flux species.

$$
\begin{aligned}
& S_{h}=\text { absorbed radiant energy } \\
& S_{L}=\text { latent heat of evaporation or condensation }
\end{aligned}
$$

The boundary conditions are given by Rahbar and co-researchers [9] are as follows

$$
\begin{aligned}
& \text { At top: } u=0, v=0, T=T_{G}, \omega_{A}=\left.\omega\right|_{T=T_{g}}=100 \% \\
& \text { At bottom: } u=0, v=0, T=T_{W}, \omega_{A}=\left.\omega\right|_{T=T_{W,}+=100 \%} \\
& \text { At the side walls: } u=0, v=0, \frac{E T}{D x}=0, \frac{E \omega_{A}}{E x}=0
\end{aligned}
$$

\section{RESULTS AND DISCUSSION}

In this session, the simulation contours of velocity, temperature, stream functions, and vapor mass fraction of water vapors of various glass cover angles of double slope solar stills such as $25^{\circ}, 35^{\circ}$, and $45^{\circ}$ were discussed. The velocity profiles of various cover angles of solar still as described in Fig. 3. 


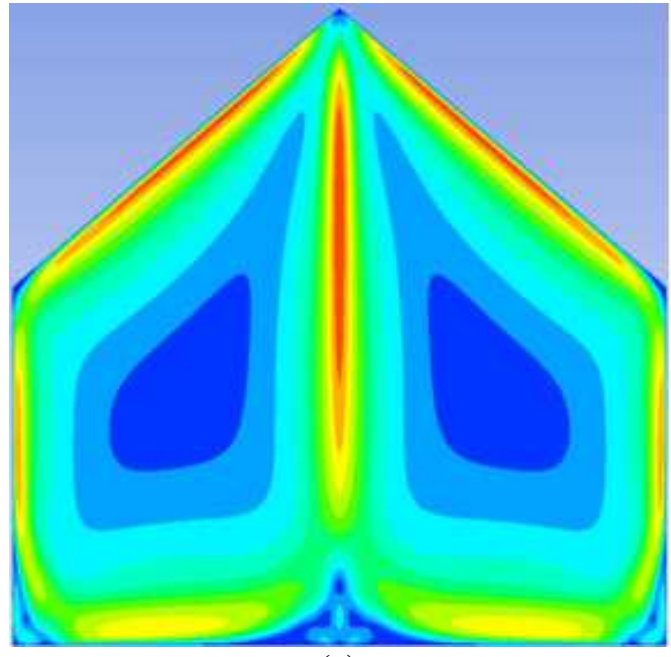

(a)

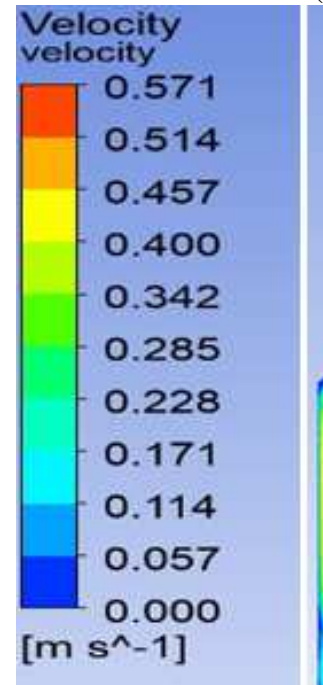

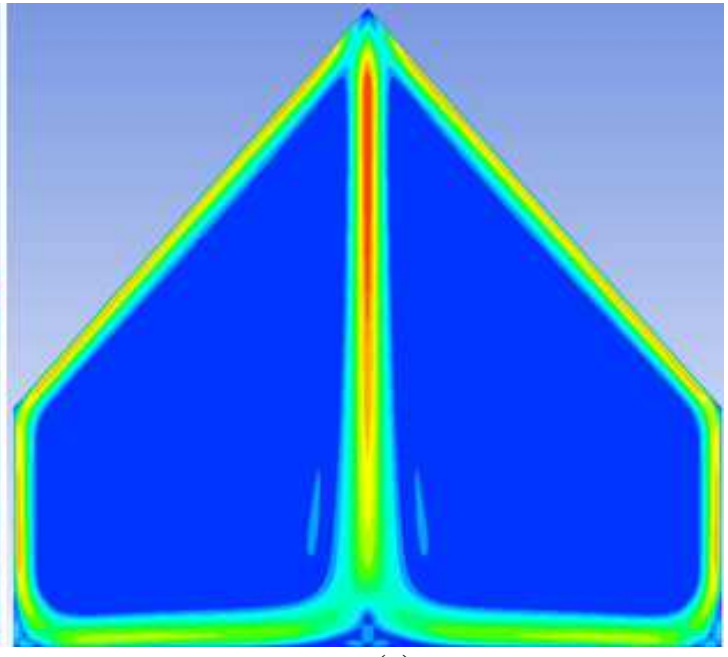

(c)

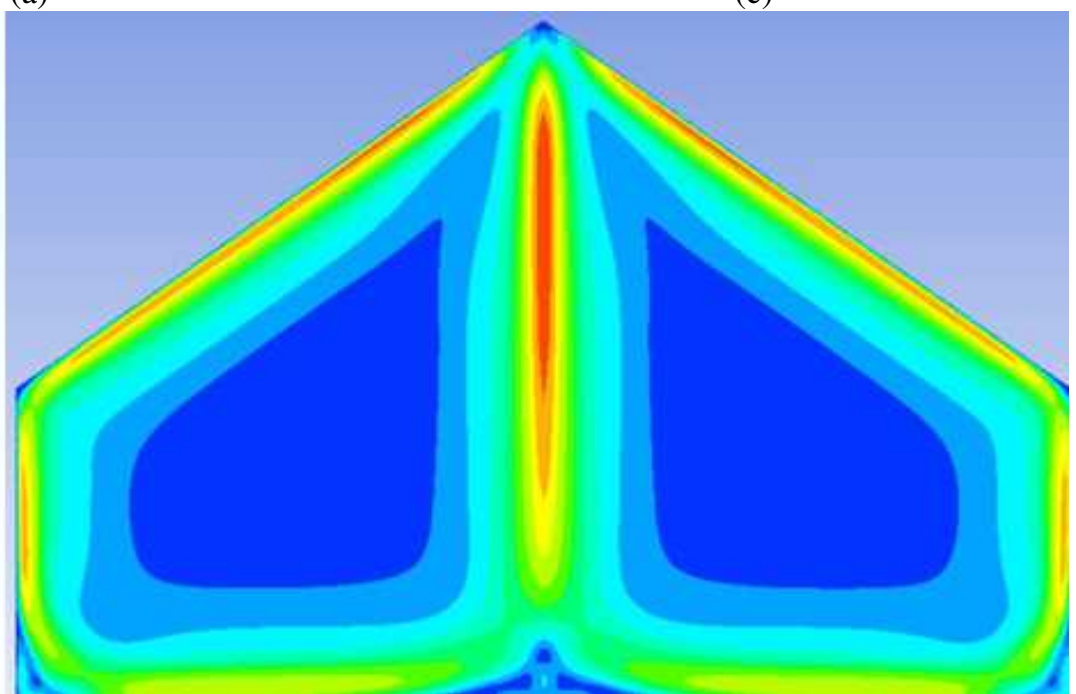

(b)

Figure 3: Velocity Contours of Different Cover Angles a.) $25^{\circ}$ b.) $35^{\circ}$ c.) $45^{\circ}$

From Fig. 3, it observed that the velocity profile distribution is optimum in $35^{\circ}$ cover angle when compared to the other glass cover inclination angles because the latitude angle of the experimental work setup was approximately equal to this optimum inclination angle.

The temperature contours of different glass cover angles are depicted in Fig. 4. And the range of temperatures was $321 \mathrm{~K}$ to $338 \mathrm{~K}$ in all the cover angles but the distribution temperature values in the solar still were optimum in the $35^{0}$ cover angle and this clearly shows the formation of isotherm curves. It was also noticed that the temperatures values in the middle of the recirculating zones were $331 \mathrm{~K}$ for $25^{0}, 325 \mathrm{~K}$ for $35^{\circ}$, and $329 \mathrm{~K}$ for $45^{\circ}$ glass cover angles respectively. 


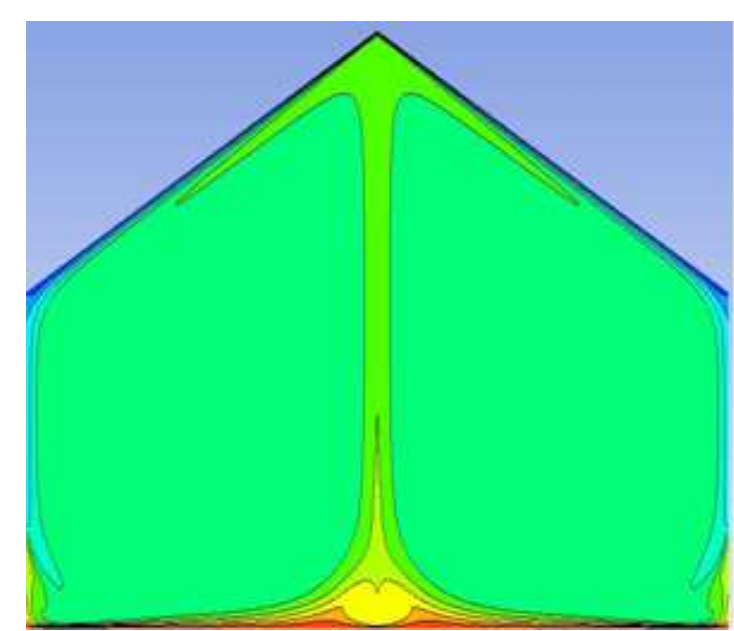

(a)

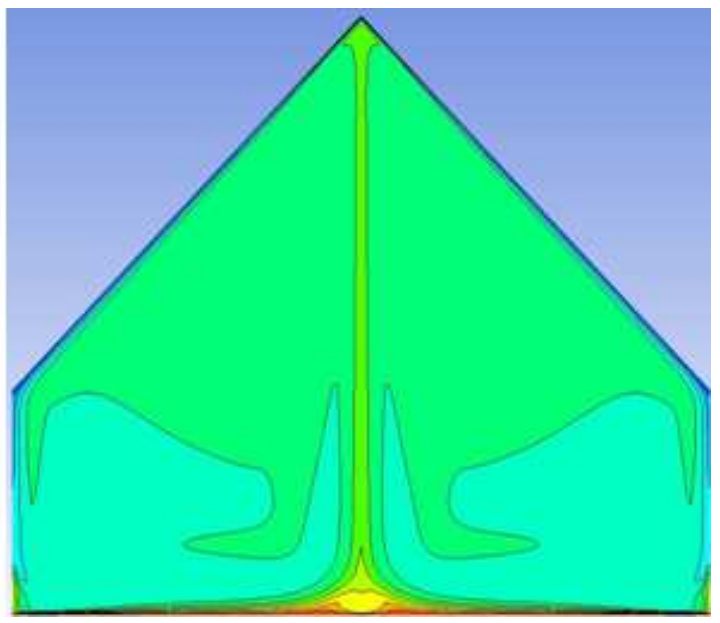

(c)

\begin{tabular}{l} 
Temperature \\
temp \\
\begin{tabular}{|l|l|}
\hline 338.000 \\
336.300 \\
334.600 \\
332.900 \\
331.200 \\
329.500 \\
327.800 \\
326.100 \\
324.400 \\
322.700 \\
321.000
\end{tabular} \\
\hline$[\mathrm{K}]$
\end{tabular}

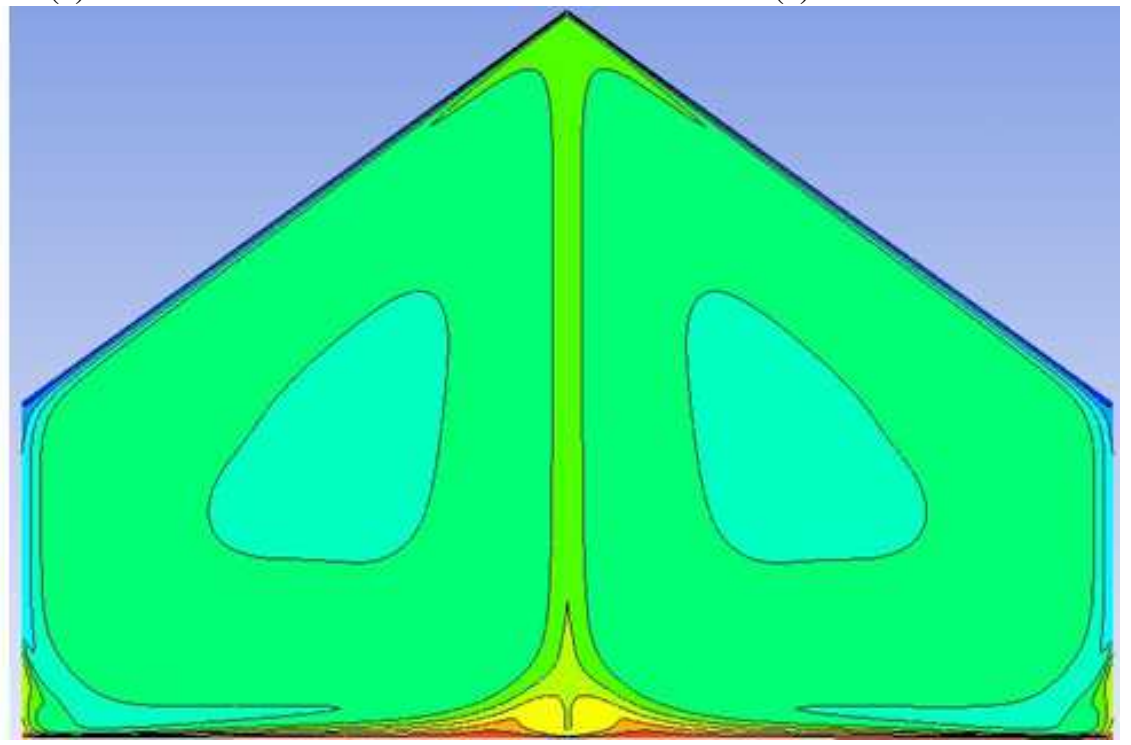

(b)

Figure 4: Temperature Contours of Different Glass Cover Angles a.) $25^{\circ}$ b.) $35^{\circ}$ c.) $45^{0}$.

The stream function contours of various glass cover angles are depicted in Fig. 5. Form the figure, it noticed that the maximum variation of streamlines formation was $0.025 \mathrm{~kg} / \mathrm{s}$ which was red color zone area and it was more in $35^{\circ}$ glass cover angle when compared to the other glass covers angles of red color zones. This clearly shows that out of three glass cover angles $35^{\circ}$ glass cover angle gives more optimum and accurate results. The heat exchange and natural convection take place inside the solar still are due to the streamlines circulation zones and these zones are helps to transport the vapor and heat between the surfaces of the water and glass cover. The fluid properties were rapidlychangingand were occurred near the glass and water surfaces because of the evaporation and condensation phenomenon. And this diminishes the amount of time required to transfer the vapor from the surface of the water to the glass cover and improves the rate of output. 


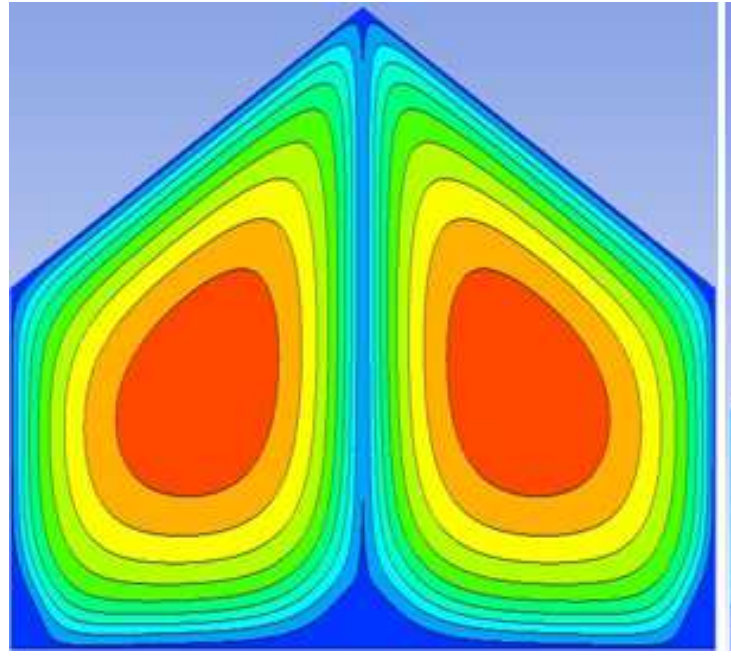

(a)

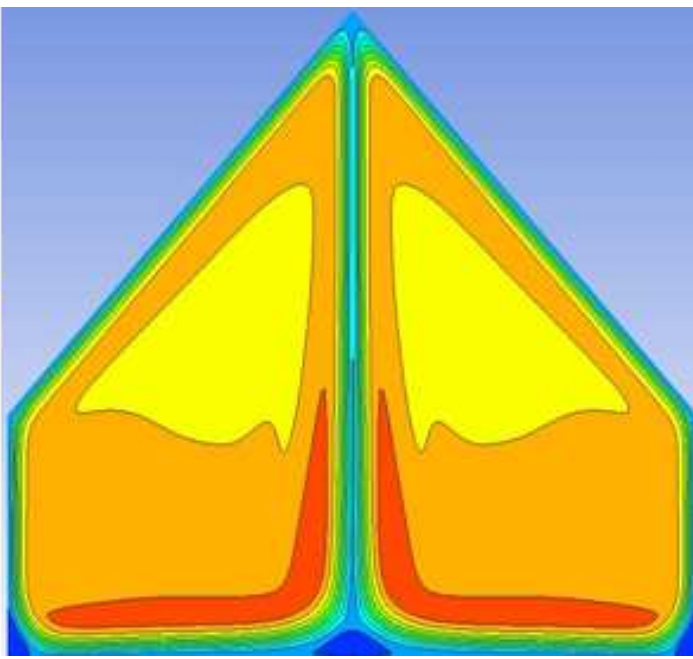

(c)

Stream Function
stream function
\begin{tabular}{|l}
0.025 \\
0.023 \\
0.020 \\
0.018 \\
-0.015 \\
0.013 \\
0.010 \\
0.008 \\
0.005 \\
0.003 \\
0.000 \\
{$\left[\mathrm{~kg} \mathrm{~s}^{\wedge}-1\right]$}
\end{tabular}

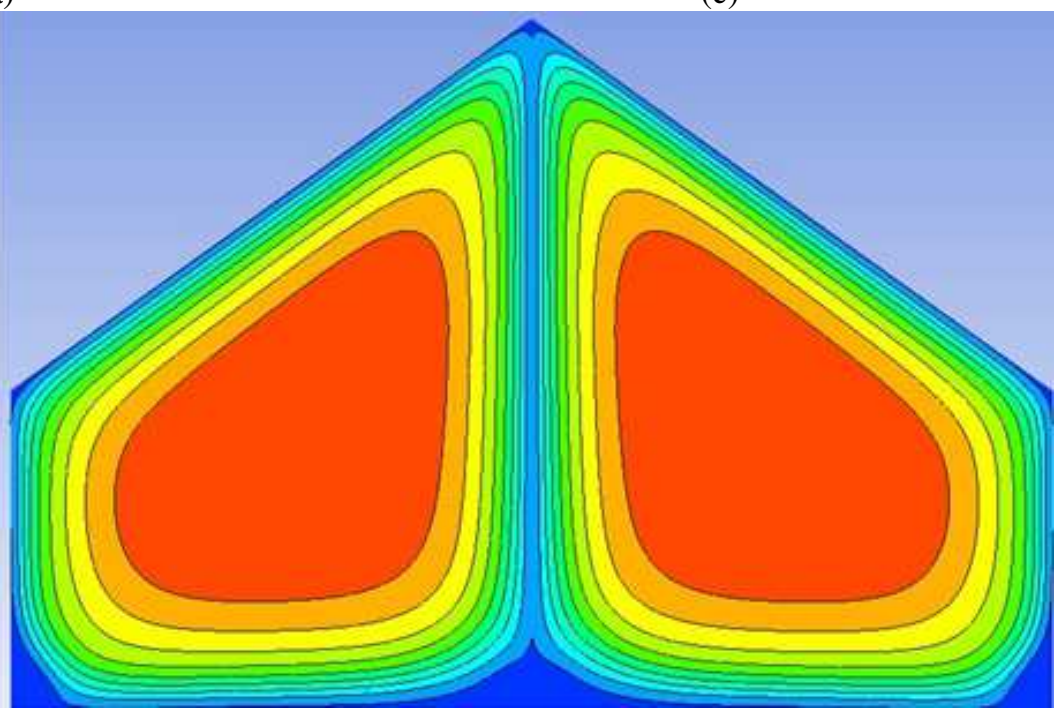

(b)

Figure. 5: Stream Function Contours of Different Glass Cover Angles a.) $25^{0}$ b.) $35^{0}$ c.) $45^{0}$.

The vapor mass fraction values of water vapor for the different glass cover angles are depicted in Fig. 6. From the figure, it noticed that the vapor mass fraction values of water vapor negligible in the center of the recirculating zones but these values were more refined at the surfaces of the glass cover and water. The most occupied value of the vapor mass fraction of water was 0.140 for $35^{\circ}$ glass cover. The thermal energy is carried by these mass fraction contour curves by providing sufficient pathways thereby enhances the mass and heat transfers between the surfaces of the glass and water. The vapor mass fraction of water vapor values was accountable for generating the evaporation and condensation phenomenon near the glass cover and water surfaces in the solar still. 

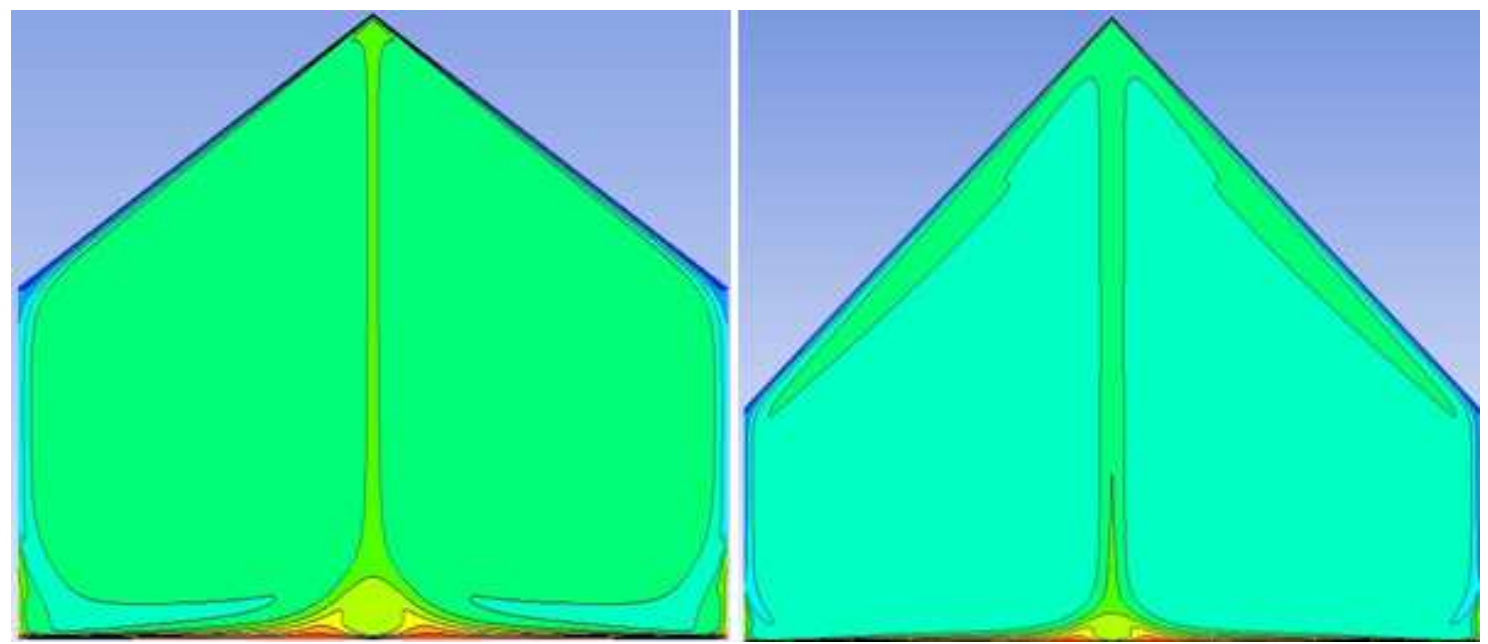

(a)

(c)
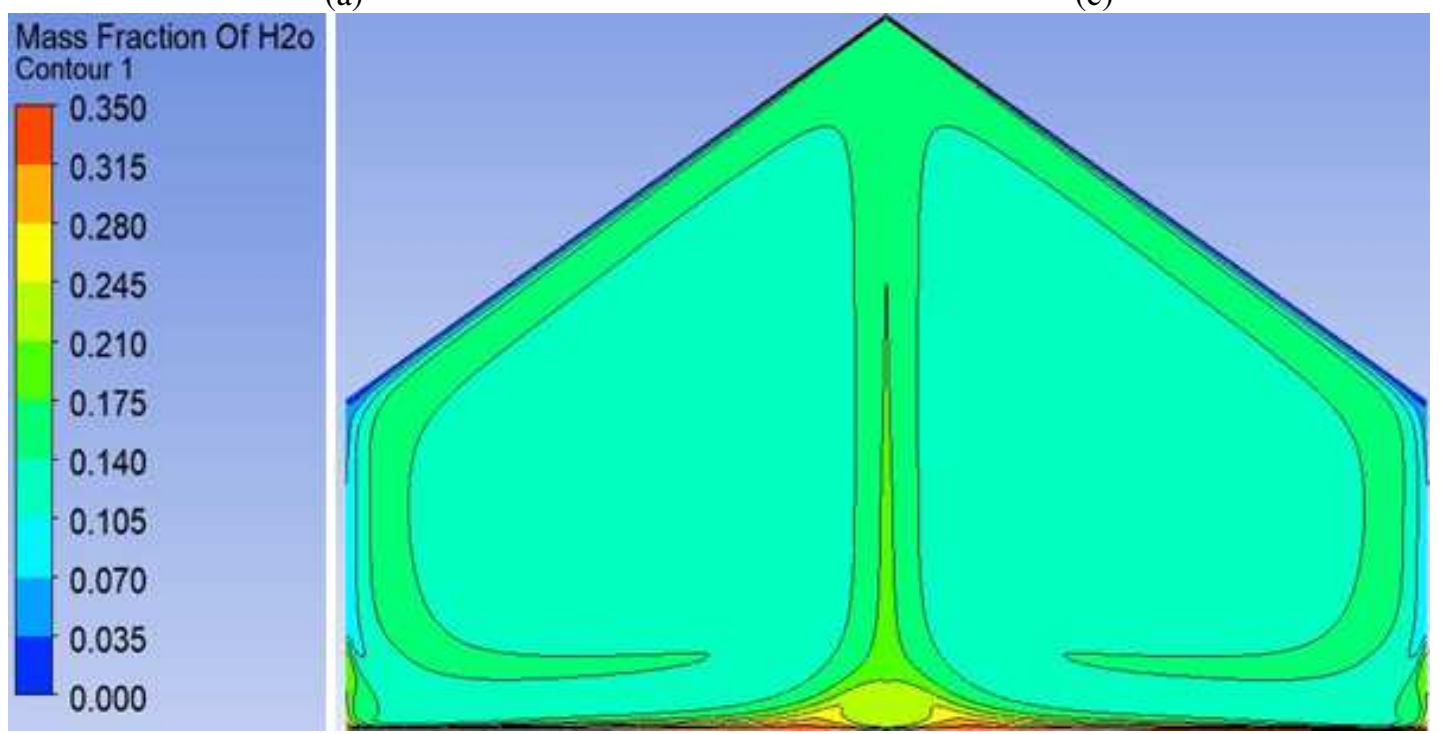

(b)

Figure 6: Vapor Mass Fraction Values of Water Vapor Contours for Different Glass Cover Angles a.) $25^{0}$ b.) $35^{0}$ c.) $45^{0}$.

Bilal et al.[12] experimentally proved that the optimum glass cover inclination angle is $35^{0}$ in contrast to other glass cover angles such as $15^{\circ}, 25^{\circ}, 45^{\circ}$, and $55^{\circ}$ respectively. In this current simulation study also, the optimum glass cover angle is $35^{\circ}$ when compared to other glass cover angles such as $25^{\circ}$ and $45^{\circ}$ respectively by evaluating the vapor mass fraction of water, velocity, temperature, and stream functions contours of various glass cover angles in the CFD Ansys Fluent simulation study.

\section{CONCLUSIONS}

- In this simulation study, an experimental work of Bilal and co-authors [12] has been simulated with the aid of CFD Ansys Fluent for evaluating the various glass cover angles of solar stills.

- The temperatures values in the middle of the recirculating zones are $331 \mathrm{~K}$ for $25^{0}, 325 \mathrm{~K}$ for $35^{\circ}$, and $329 \mathrm{~K}$ for $45^{\circ}$ glass cover angles respectively.

- The maximum variation of streamlines formation value is $0.025 \mathrm{~kg} / \mathrm{s}$ which is in red color zone area is more in $35^{0}$ glass cover angle when compared to the other glass covers angles of red color zones. 
- The vapor mass fraction contour curves carry the thermal energy by providing sufficient pathways thereby enhances the mass and heat transfers between the surfaces of the glass and water.

\section{ACKNOWLEDGEMENTS}

The authors are grateful to VNR Vignana Jyothi Institute of Engineering and Technology for providing the facilities to simulate the CFD Ansys Fluent. The authors are also very grateful to the reviewers for sparing their valuable time.

\section{REFERENCES}

1. Delyannis E. Historic background of desalination and renewable energies 2003;75:357-66.

2. Selvaraj K, Natarajan A. Factors influencing the performance and productivity of solar stills - A review. Desalination 2018;435:181-7.

3. Vishwanath Kumar P, Kumar A, Prakash O, Kaviti AK. Solar stills system design: A review. Renew Sustain Energy Rev 2015;51:153-81.

4. Mohan I, Yadav S, Panchal H, Brahmbhatt S. A review on solar still: a simple desalination technology to obtain potable water. Int J Ambient Energy 2019;40:335-42.

5. Ullah I, Rasul MG. Recent developments in solar thermal desalination technologies: A review. Energies 2019;12.

6. Kaviti AK, Yadav A, Shukla A. Experimental investigation of solar still with an opaque north triangular face. Int J Green Energy 2019;0:1-8.

7. Rahbar N, Abolfazli J, Fotouhi-bafghi E. Estimation of convective heat transfer coefficient and water-productivity in tubular solar still - CFD simulation and theoretical analysis. Sol Energy 2015;113:313-23.

8. Rashidi S, Bovand M, Esfahani JA. Optimization of partitioning inside single slope solar still for performance improvement. DES 2016;395:79-91.

9. Rahbar N, Esfahani JA. Estimation of the convective heat transfer coefficient in a single-slope solar still: A numerical study. Desalin Water Treat 2012;50:387-96.

10. Rahbar N, Esfahani JA. Productivity estimation of a single-slope solar still: Theoretical and numerical analysis. Energy 2013;49:289-97.

11. Keshtkar M, Eslami M, Jafarpur K. A novel procedure for transient CFD modeling of basin solar stills: Coupling of species and energy equations. Desalination 2020;481:114350.

12. Akash BA, Mohsen MS, Nayfeh W. Experimental study of the basin type solar still under local climate conditions. Energy Convers Manag 2000;41:883-90.

13. Keshtkar M, Eslami M, Jafarpur K. Effect of design parameters on the performance of passive basin solar stills considering instantaneous ambient conditions: A transient CFD modeling. Sol Energy 2020;201:884-907.

14. S. Shanmugan, "Experimental Analysis of a Single Slope Single Basin Solar Still with Hot Water Provision", International Journal of Applied and Natural Sciences (IJANS), Vol. 3, Issue 1, pp. 19-24

15. S. R. Kalbande, Priyanka Nayak, Sneha Deshmukh \& V. P. Khambalkar, "Thermal Evaluation of Solar Water Desalination System with Evacuated Tubes “, International Journal of Applied and Natural Sciences (IJANS), Vol. 6, Issue 1,pp. 41-54 
16. Wactaw Kollek \& Urszula Radziwanowska, "The Modernization of Gear Micropump Casing with the Use of Finite Element Method “, IMPACT: International Journal of Research in Engineering \& Technology (IMPACT: IJRET), Vol. 2, Issue 7, pp. 69-76

17. Vivek Bharat Pattni, P. Naveenchandran, C. Thamotharan \& R. Rajasekar, "HCCI Combustion: Mathematical Modelling Approach Using Visual Basic for Applications “, BEST: International Journal of Management, Information Technology and Engineering (BEST: IJMITE), Vol. 2, Issue 5, pp. 1-8 